\title{
Operando electrochemical SERS monitors nanoparticle reactions by capping agent fingerprints
}

\author{
Kevin Wonner ${ }^{1, \S}$, Steffen Murke ${ }^{2, \S}$, Serena R. Alfarano ${ }^{2}$, Pouya Hosseini ${ }^{1}$, Martina Havenith ${ }^{2}(\varangle)$, and Kristina \\ Tschulik $^{1}(\triangle)$ \\ ${ }^{1}$ Chair of Analytical Chemistry II, Faculty of Chemistry and Biochemistry, Ruhr University Bochum, Bochum 44801, Germany \\ ${ }^{2}$ Chair of Physical Chemistry II, Faculty of Chemistry and Biochemistry, Ruhr University Bochum, Bochum 44801, Germany \\ ${ }^{\S}$ Kevin Wonner and Steffen Murke contributed equally to this work.
}

(C) The Author(s) 2021

Received: 14 July 2021 / Revised: 4 October 2021 / Accepted: 24 October 2021

\begin{abstract}
Nanomaterials are frequently employed in daily life goods, including health, textile, and food industry. A comprehensive picture is lacking on the role of the capping agents, added ligand molecules, in case of nanoparticle reactions and degradation in aqueous solutions, like surface waters or biofluids. Here, we aim to elucidate the capping agent influence on nanoparticle reactivity probing two commonly employed capping agents citrate and polyvinylpyrrolidone (PVP). Their influence on silver nanoparticle (AgNP) transformation is studied, which is particularly important due to its application as an antimicrobial agent. We induce oxidation and reduction processes of AgNPs in halide solutions and we monitor the associated transformations of particles and capping agents by spectro-electrochemical surface-enhanced Raman spectroscopy (SERS). Raman bands of the capping agents are used here to track chemical changes of the nanoparticles under operando conditions. The sparingly soluble and non-plasmon active silver salts $(\mathrm{AgBr}$ and $\mathrm{AgCl})$ are formed under potential bias. In addition, we spectroscopically observe plasmon-mediated structural changes of citrate to cis- or trans-aconitate, while PVP is unaltered. The different behavior of the capping agents implies a change in the physical properties on the surface of AgNPs, in particular with respect to the surface accessibility. Moreover, we showcase that reactions of the capping agents induced by different external stimuli, such as applied bias or laser irradiation, can be assessed. Our results demonstrate how SERS of capping agents can be exploited to operando track nanoparticle conversions in liquid media. This approach is envisaged to provide a more comprehensive understanding of nanoparticle fates in complex liquid environments and varied redox conditions.
\end{abstract}

\section{KEYWORDS}

capping agent, electrochemical surface-enhanced Raman spectroscopy, silver nanoparticle, nanoparticle reaction

\section{Introduction}

Due to their advantageous physical, antimicrobial, and often anti-inflammatory properties, the application of nanomaterials increased widely in various fields during the last decades, spanning from food [1], medicine [2-4], clothing [5,6], and agricultural sectors $[7,8]$ to industrial applications for energy conversion and storage $[9,10]$ and use in medicine and biology $[2,3,11]$ as well as catalyst materials [12-16]. Thus, there is a high demand to understand those materials in detail and in particular the processes that can occur at the nanoscale surface. Nanomaterials show physical properties that may strongly differ from the corresponding bulk material [17]. For instance, their high surface-to-volume ratio makes them ideal candidates as highly active heterogeneous catalysts or sensitive sensor components $[18,19]$. However, nanoparticle engineering usually requires the use of capping agents to adjust their sizes and shapes to prevent agglomeration [20].

In order to provide a microscopic and macroscopic description and gain deeper insights into the associated processes, coupling an electrochemical experiment with a spectroscopic technique is often highly beneficial. Fruitful combinations include dark-field microscopy [21-26], fluorescence microscopy [27, 28], electrogenerated chemiluminescence [29-31], surface plasmon resonance imaging [32-34] and surface-enhanced Raman spectroscopy (SERS) [35-40]. The latter is of crucial importance to investigate the electrode/electrolyte interface involved in a reaction at a molecular level $[41,42]$.

In a SERS experiment, the impinging laser excites a nanostructured surface, inducing a plasmonic light field, thereby enhancing the local electric field. SERS has been employed to probe the effect of geometrical properties (like the size) of nanostructures [43] and to sensitively track the electrochemical reaction of different reactants on SERS active structures used as working electrodes in electrochemical experiments [44-46].

$\mathrm{Au}$ or $\mathrm{Ag}$ is typical SERS substrates and their activation (increase of the enhancement factor) is optimized by electrochemical roughening, metallic coating of a nanostructured substrate, or deposition of metallic nanoparticles [47,48]. In particular, silver nanoparticles (AgNPs) and gold nanoparticles (AuNPs) are noble metal nanomaterial sources commonly employed in SERS, because of their high plasmon activity [49-52], 
stability, and capability to catalyse reaction $[53,54]$ or even reacting themselves [55]. Here, we report SERS results using AgNPs, whose electrochemical oxidation is of broad interest and has been studied intensely in the recent past [21-23,25,26, 56-58].

Remarkably, methods like dark-field microscopy or surface plasmon resonance imaging are able to resolve processes at a single particle level and shed light on the oxidation mechanism (e.g., stepwise or instantaneous oxidation under different conditions) $[21,23,24,28]$. However, the reported oxidation mechanism and product formation strongly depend on the individual experimental conditions [59-63]. This may partially arise from the fact that typically little attention is drawn to the role of the capping agent, present in the vast majority of nanoparticle studies.

Accordingly, in this study we explore the role of capping agents on nanoparticle reactivity using SERS and electrochemistry as two complementary surface sensitive techniques.

Previous works in this direction utilized capping agents as calibrating molecules [64-67], molecular antennas to monitor the electrochemical reaction of the nanoparticle $[32,68]$, capping agent reaction $[69,70]$, or reported an influence of the capping agent on their catalytic activity [71-78].

While it is obvious that these surface-bound species will influence the physical properties [79], reactivity, and degradation of nanomaterials, it remains unclear how and to which extent this happens. In this work, we shed light on the role of citrate and polyvinylpyrrolidone (PVP) capping agents, by probing particle conversion operando. During the electrochemical oxidation and reduction of silver nanoparticles, we monitor their corresponding active Raman bands with SERS.

\section{Experimental section}

\subsection{Electrochemical measurements}

High-performance liquid chromatography (HPLC) grade ultra-pure water at $23{ }^{\circ} \mathrm{C}$ was used for preparation of aqueous solutions and cleaning processes. Potassium chloride $(\mathrm{KCl}, \mathrm{P} 9333$, purity of $\geq 99.0 \%$ ) and potassium bromide ( $\mathrm{KBr}, \mathrm{P} 0838$, purity of $\geq 99.0 \%$ ) were purchased from Sigma-Aldrich. We employed a $\mathrm{Au}$ disc with a diameter of $1.4 \mathrm{~cm}$ (Plano $\mathrm{GmbH}$, purity $\geq 99.0 \%$ ) as working electrode (WE), a Pt gauze (ChemPur Feinchemikalien und Forschungsbedarf $\mathrm{GmbH}, 0.04 \mathrm{~mm}$ wire diameter, purity of 99.9\%) as counter electrode (CE) and a $\mathrm{Ag} / \mathrm{AgCl}(3 \mathrm{M} \mathrm{KCl})$ reference electrode (RE), customized by Sensolytics $\mathrm{GmbH}$.

Silver nanoparticles were purchased from nanoComposix Inc. and AgNPs with a diameter of $29 \pm 3 \mathrm{~nm}$ (transmission electron microscopy (TEM) measurements) were capped with either citrate or PVP, resulting in a hydrodynamic mean diameter of 34 or $51 \mathrm{~nm}$, respectively. Furthermore, AgNPs with a size of $51 \pm 6 \mathrm{~nm}$ (TEM) were capped with citrate, resulting in a hydrodynamic mean diameter of $51 \mathrm{~nm}$. TEM images of the particles are shown in Figs. S1-S3 in the Electronic Supplementary Material (ESM).

All electrochemical measurements were performed with a PalmSens 4 (PalmSens BV) potentiostat. The working electrode was grinded initially with $\mathrm{SiC}$ paper, reducing the grit from 2,000 to $3,000,5,000$, and 7,000, respectively, and then polished for 5 min with alumina powder (size of $1,0.3$, and $0.05 \mu \mathrm{m}$, Buehler: MicroPolish Alumina Suspension) on a polishing cloth (Buehler ChemoMet) for $5 \mathrm{~min}$. After each polishing step, the electrode was sonicated in ultrapure water for $5 \mathrm{~min}$.

A volume of $20 \mu \mathrm{L}$ of nanoparticle suspension with a mass concentration of $\mathrm{Ag}$ of $0.021 \mathrm{~g} \cdot \mathrm{L}^{-1}$ for citrate-capped 30 and $50 \mathrm{~nm}$ AgNPs and of $0.022 \mathrm{~g} \cdot \mathrm{L}^{-1}$ for PVP-capped $30 \mathrm{~nm}$ particles was drop cast on the electrode and dried. The particle concentration was provided by the supplier, resulting in a theoretical particle number on the surface of $3.2 \times 10^{9}, 6.0 \times 10^{8}$, and $3.4 \times 10^{9}$, respectively. For electrochemical control experiments, a commercial $2 \mathrm{~mm}$ diameter $\mathrm{Au}$ disc was employed as a WE, a graphite rod as a $\mathrm{CE}$ and a $\mathrm{Ag} / \mathrm{AgCl}(3.0 \mathrm{M} \mathrm{KCl})$ as a $\mathrm{RE}$ with a total volume of $0.408 \mu \mathrm{L}$ of nanoparticles solution drop cast on the $\mathrm{WE}$, to achieve comparable nanoparticle coverage of the WE.

For electrochemical SERS measurements in $50 \mathrm{mM} \mathrm{KCl}$, a potential of $0.05 \mathrm{~V}$ was held for $20 \mathrm{~s}$, then increased with a scan rate of $0.002 \mathrm{~V} \cdot \mathrm{s}^{-1}$ to $0.4 \mathrm{~V}$ and held there for $20 \mathrm{~s}$. Then, the potential was reversed to $-0.2 \mathrm{~V}$ with a scan rate of $0.002 \mathrm{~V} \cdot \mathrm{s}^{-1}$ and held there for $20 \mathrm{~s}$. Three consecutive runs were performed. Control measurements without laser irradiation were recorded at identical potentials.

In $50 \mathrm{mM} \mathrm{KBr}$ solution, potentials were swept from -0.1 to $0.25 \mathrm{~V}$ in the forward scan and set to $-0.3 \mathrm{~V}$ in the backward direction, taking into account the change of formal potential of $\mathrm{Ag} / \mathrm{AgBr}$ in comparison to $\mathrm{Ag} / \mathrm{AgCl}$ [80]. The lower potential limit was selected to avoid oxygen reduction reaction as a possible side reaction at the WE. The initial, the turning and the final potentials were held for $20 \mathrm{~s}$, each. Control measurements were conducted without laser radiation and any particles to exclude non-particle related contributions in the current signal.

\subsection{Raman spectroscopy}

For the surface-enhanced Raman measurements, a WITec (Ulm, Germany) Alpha 300 RSA Plus Raman microscope was combined with a home built electrochemical cell. A schematic drawing of the electrochemical cell and its details can be found in Fig. S4 in the ESM.

The excitation source is a $532 \mathrm{~nm} \mathrm{Nd:YAG} \mathrm{laser.} \mathrm{A} 60 \times$ water immersion objective (Nikon, NIR Apo, 60×/1.0W) was used during all the experiments. $50 \mu \mathrm{L}$ of ultrapure water was dropped on the lens and then the objective was covered with a fluorinated ethylene propylene (FEP) foil for protection (corrosive solutions or interference during electrochemical measurements). A $25 \mu \mathrm{m}$ multimode glass fiber was used as pinhole aperture, which directed the light onto a dispersion grating $\left(600\right.$ lines $\left.\cdot \mathrm{mm}^{-1}\right)$. An electron-multiplied charge-coupled device (EMCCD) with $1,600 \times$ 200 active pixels was used as detector and the raw spectra were recorded in a range from 150 to $3,600 \mathrm{~cm}^{-1}$ (spectral resolution $<4 \mathrm{~cm}^{-1}$ ). Each spectrum was recorded with $17 \mathrm{~mW}$ laser power, and $1 \mathrm{~s}$ integration time. For the final displayed measurement 20 spectra were averaged. In addition, eventual cosmic rays were removed, and a background correction was performed.

\section{Results and discussion}

\subsection{Role of particle size and electrolyte solution}

In this work, we used electrochemical SERS (EC-SERS) experiments to quantify the influence of the capping agent on the oxidation/reduction of silver nanoparticle in situ and operando, the dependency of the particle size, and type of anion in the surrounding liquid medium.

Initially, citrate-capped AgNPs in chloride solutions with representative size of 30 and $50 \mathrm{~nm}$ were investigated. A SERS spectrum in the frequency range of citrate fingerprints was acquired every $20 \mathrm{~s}$ of the cyclic voltammetry (CV) scan, as described in the Experimental section. Figure 1(a) shows the current of a representative forward and backward sweep of a cycle as a function of the applied potential for $30 \mathrm{~nm}$ (in blue) and $50 \mathrm{~nm}$ (in red) AgNPs. The associated full potential and current plots as a function of time are provided in Figs. S5 and S6 in the 

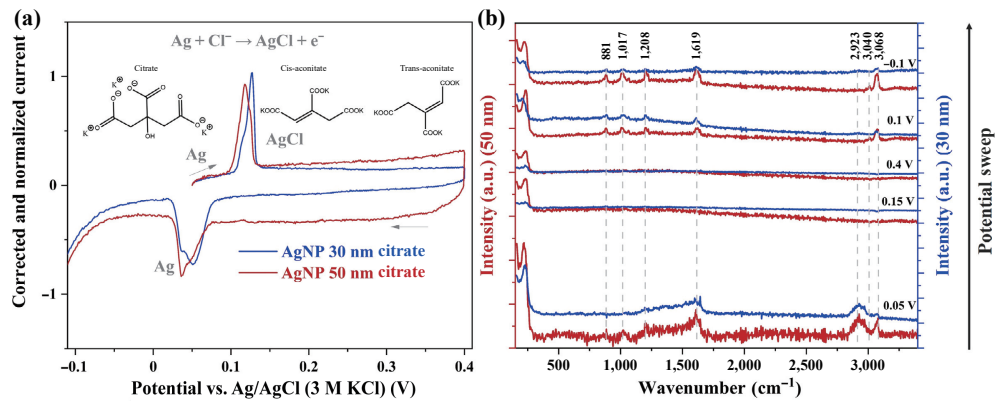

Figure 1 (a) Current potential diagram in $50 \mathrm{mM} \mathrm{KCl}$ for $30 \mathrm{~nm}$ (blue) and $50 \mathrm{~nm}$ (red) Ag nanoparticles. The inset shows the structural formula of citrate and cisand trans-aconitate. (b) SERS spectra at representative potentials of the first cycle for $30 \mathrm{~nm}$ AgNPs (blue) and $50 \mathrm{~nm}$ AgNPs (red) in $50 \mathrm{mM}$ KCl. Raman modes assigned to citrate are highlighted.

ESM for both particle sizes for all cycles. SERS spectra at representative potentials are shown in Fig. 1(b). The complete spectral dataset are shown in Figs. S7 and S8 in the ESM. In the frequency range from $800-3,200 \mathrm{~cm}^{-1}$, characteristic stretching modes of the citrate ions are detected at $881,1,017,1,208,1,619$, and $2,923 \mathrm{~cm}^{-1}$. For assignment, density functional theory (DFT) calculations were performed for citrate and the results are summarized in Table S1 in the ESM and compared to literature values (Table S2 in the ESM). In general, the observed spectral features for both samples, i.e., 30 and $50 \mathrm{~nm}$ particles show the same spectral response (Fig. 1(b)). The vibrational modes are assigned as follows: $881\left(\mathrm{vC}-\mathrm{COO}^{-}\right), 1,017\left(\mathrm{vCOO}^{-}\right), 1,208$ (vCCO), 1,619 $\left(\mathrm{vCO}_{2}\right)$, and $2,923 \mathrm{~cm}^{-1}\left(\mathrm{vCH}_{2}\right)$. The bands centered around $3,040(v=\mathrm{CH})$ and $3,068 \mathrm{~cm}^{-1}(\mathrm{v}=\mathrm{CH})$ are attributed to the Raman modes derived from the double bond of an already at the beginning formed aconitate by laser irradiation [81].

For both particle sizes, the bands associated to the citrate ions disappear at potentials higher than $0.15 \mathrm{~V}$. In the electrochemical current response an oxidation peak is detected at around $0.12 \mathrm{~V}$ (cfr Fig. 1(a)) and it is assigned to the electrochemical oxidation of AgNPs. We can assume that the loss of the Raman signal is likely due to the loss of the SERS active nanostructures of plasmon active AgNPs or the detachment of the capping agent. Since the reaction is conducted in chloride solution, AgNPs are not electrochemically dissolved to $\mathrm{Ag}^{+}(\mathrm{aq})$, but the sparingly soluble non-plasmon active silver chloride $(\mathrm{AgCl})$ is formed during the reaction (vide infra, Eq. (1)) [22, 82, 83].

$$
\mathrm{Ag}+\mathrm{Cl}^{-}(\mathrm{aq}) \rightleftharpoons \mathrm{AgCl}(\mathrm{s}) \downarrow+\mathrm{e}^{-}
$$

Upon sweeping back the potential to lower values, a reduction of $\mathrm{AgCl}$ back to $\mathrm{Ag}$ is detected in the electrochemical response at about $0.05 \mathrm{~V}$ during the reversed scan, as the oxidation and reduction of silver in the presence of chloride are known to be almost reversible (Fig. 1(a)) [22,83]. Simultaneously to the re-formation of Ag, Raman bands of the citrate ion re-occur in the spectroscopic signal plotted in Fig. 1(b) for both nanoparticle sizes. Thus, it can be assumed that the capping agent still binds to the particle surface throughout the experiment and does not detach during the reaction. Since each displayed spectrum is the result of 20 averaged spectra acquired for $1 \mathrm{~s}$ each, no dynamic desorption and adsorption processes can be resolved in time, but time-averaged values are obtained. We conclude that the loss of the SERS signal is attributed to the loss of plasmonic activity upon conversion of $\mathrm{Ag}$ to $\mathrm{AgCl}$, based on the simultaneous loss/recovering of the citrate signals upon oxidation/reduction. Additional cyclic voltammogram control experiments were first run without laser irradiation and later without AgNPs in $50 \mathrm{mM}$ $\mathrm{KCl}$ solution, showing that in the latter case neither an oxidation nor any reductions signal can be detected (Figs. S9 and S10 in the ESM, respectively). This demonstrates that the oxidation/reduction is laser-independent, and it is solely attributed to the presence of NPs.

Notably, the band assigned to the asymmetric $\mathrm{CH}_{2}$ stretch (2, $923 \mathrm{~cm}^{-1}$ ) can no longer be detected after the oxidation and the subsequent reduction, while a weak band emerges at $3,040 \mathrm{~cm}^{-1}$, assigned to the asymmetric $=\mathrm{CH}$ stretching mode (Table $\mathrm{S} 1$ and Fig. S11 in the ESM). In addition, the band at $3,068 \mathrm{~cm}^{-1}$ becomes more pronounced. This band is assigned to the asymmetric $=\mathrm{CH}$ stretch of aconitate, a reaction product of citrate ions. Previously, Takeuchi et al. [81] found that the plasmon-mediated oxidation of decylamine on the SERS surface of Ag nanoparticles occurs without any potential application. Here, we postulate the conversion from alkane (citrate) to alkene (trans- or cis-aconitate), revealed from the evolution of the asymmetric $\mathrm{CH}_{2}\left(2,923 \mathrm{~cm}^{-1}\right)$ and asymmetric $=\mathrm{CH}$ stretching bands $\left(3,068 \mathrm{~cm}^{-1}\right)$ as a consequence of the laser radiation exposure.The intensity of the asymmetric $=\mathrm{CH}$ stretch $\left(3,068 \mathrm{~cm}^{-1}\right)$ increases (doubling the intensity from cycle 1 to cycle 2) with an increasing number of potential cycles and thus also with increasing time, which indicates an ongoing oxidation of the capping agent. The band at $3,068 \mathrm{~cm}^{-1}$ in the initial spectrum at $0.05 \mathrm{~V}$ is related to the ongoing spontaneous photoreaction of the capping agent. Raman control spectra of pure citrate sample on a Raman graded $\mathrm{CaF}_{2}$-wafer in the absence of nanoparticles acquired after $30 \mathrm{~min}$ of laser exposure at $17 \mathrm{~mW}$ (Fig. S12 in the ESM) exhibit no band for the asymmetric $=\mathrm{CH}$ stretch at $3,068 \mathrm{~cm}^{-1}$, confirming that the band arises upon oxidation of citrate only in the presence of a nanoparticle as mediator.

Complementary DFT calculations were performed for cis- and trans-aconitate, confirming the assignments of the band at $3,068 \mathrm{~cm}^{-1}$ to the formation of a double bond of the alkene (Tables S3 and S4 in the ESM). From DFT calculation, the trans-aconitate state is approximately $3 \mathrm{kcal}$ more stable than the cis-product. Hence, it can be assumed that trans-aconitate formation is more favourable.

To confirm whether the capping agent remains bound to the particle surface irrespective of the particles' oxidation state or whether it detaches from the oxidized particles and reattaches to the surface of particles during the reduction of $\mathrm{AgCl}$ to silver, additional control experiments have been performed. The oxidative potential was kept at $0.4 \mathrm{~V}$ for $900 \mathrm{~s}$ before reversing the sweep direction in a CV scan (Fig. S13 in the ESM). While no Raman modes of citrate ions (ranging from 881 to $3,068 \mathrm{~cm}^{-1}$ ) were detected within the $900 \mathrm{~s}$, where we fixed the potential, while these modes were instantaneously restored when sweeping back the potential ( $c f r$ Fig. 1). In contrast, any diffusion of the citrate molecules, initiated by the application of a constant (relatively) high potential would have caused a complete loss of the ion into the electrolyte solution. Thus, we can exclude the detachment or desorption of the capping agents from the nanoparticle upon oxidation and confirm that the loss of the bands associated with 

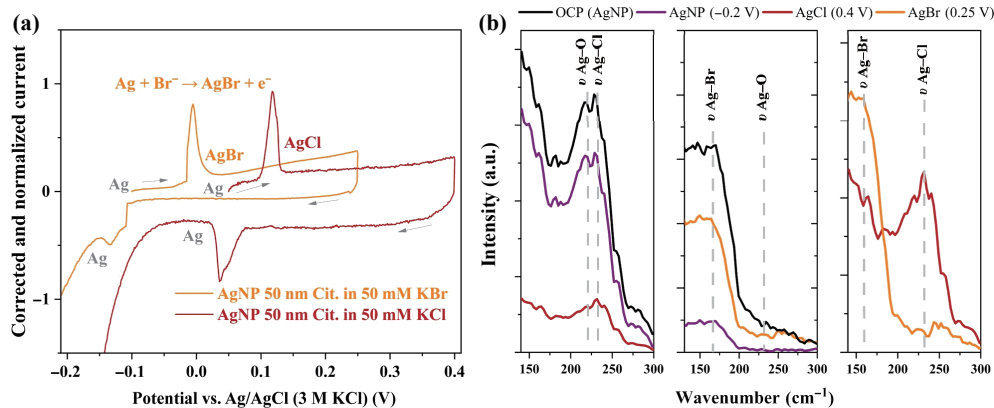

Figure 2 (a) Current potential diagram of $50 \mathrm{~nm}$ citrate-capped AgNPs in $50 \mathrm{mM} \mathrm{KBr}$ (orange) and in $50 \mathrm{mM} \mathrm{KCl}$ (red). The potential was swept with $0.002 \mathrm{~V} \cdot \mathrm{s}^{-1}$ between 0.05 and $0.4 \mathrm{~V}$ for chloride solutions and -0.1 and $0.25 \mathrm{~V}$ for bromide solutions. (b) Comparison of SERS spectra of $50 \mathrm{~nm}$ citrate-capped AgNPs in $50 \mathrm{mM} \mathrm{KCl}$ (left) and in $50 \mathrm{mM} \mathrm{KBr}$ (middle) for selected potentials (black: AgNP at OCP; violet: AgNP at $-0.2 \mathrm{~V}$; red: AgCl at $0.4 \mathrm{~V}$; orange: AgBr at $0.25 \mathrm{~V}$ ) in the frequency range from 100 to $300 \mathrm{~cm}^{-1}$. In the right panel in (b) we compared the spectra of $\mathrm{AgCl}$ (red) and $\mathrm{AgBr}$ (orange). Generally, the OCP value was in the range of 0 to $-0.2 \mathrm{~V}$ and was, thus, more negative than the applied starting potential. OCP denotes the voltage for which only a negligible current is flowing. A reaction of the nanoparticles can be excluded.

the capping agent is caused by the formation of non-SERS active $\mathrm{AgCl}$ nanostructures.

Both the $=\mathrm{CH}$ stretching band and the $-\mathrm{CH}_{2}$ stretching band of the aconitate are still present and did not alter after the application of a constant oxidative potential for $900 \mathrm{~s}$. Thus, we conclude that aconitate is formed via laser irradiation at the reduced particle state and not by electrochemical oxidation.

In previous works, the formation of $\mathrm{AgCl}$ during the oxidation was reported in Refs. $[21,23,82,83]$. In Fig. 2(b), we zoom into the spectral region between 100 and $300 \mathrm{~cm}^{-1}$, which includes the silver-oxygen stretching mode ( $\mathrm{OAg}-\mathrm{O}$, first panel black curve) at around $220 \mathrm{~cm}^{-1}$. The silver chloride stretching mode is plotted for comparison [84]. We found clear evidence for the presence of this mode for $30 \mathrm{~nm}$ as well as $50 \mathrm{~nm}$ AgNPs. At $\mathrm{pH}=7$, no silver oxide is expected for the given potentials smaller than $0.4 \mathrm{~V}$ ( $c f r$ the Pourbaix diagram of silver in chloride solution) [85]. Therefore, we conclude that the silver-oxygen mode reports on the interaction of the silver particles with the surrounding citrate ion.

For a potential of $-0.2 \mathrm{~V}$ (violet) the intensity of the $\mathrm{Ag}-\mathrm{O}$ band is decreased compared to the open circuit potential (OCP, black). At the OCP potential at which no external potential is applied and, thus we can exclude detection of any reaction product. This can be explained by a small increase in the distance between the capping agent and the Ag particle due to repulsive interactions with the negatively charged citrate ion and the negatively polarised nanoparticle, resulting in a surface damping of the plasmon resonance [86-89]. Upon increase of the potential to $0.4 \mathrm{~V}$, the $\mathrm{Ag}-\mathrm{O}$ band at $220 \mathrm{~cm}^{-1}$ is no longer visible, while the $\mathrm{Ag}-\mathrm{Cl}$ band at $240 \mathrm{~cm}^{-1}$ increases (red spectrum, Fig. 2(b)), indicating the formation of poorly soluble $\mathrm{AgCl}(\mathrm{s})$ [90]. This is observed independently of the particle size.

In order to confirm the silver salt formation, an additional halide-containing electrolyte $(50 \mathrm{mM} \mathrm{KBr})$ for the coupled oxidation of $50 \mathrm{~nm}$ citrate-capped AgNPs was used. Since the formal potential of the silver/silver halide redox couple differs for different halide solutions [80], the potential was swept from -0.10 to $0.25 \mathrm{~V}$ and back to $-0.3 \mathrm{~V}$ to account for the lower formal potential of $\mathrm{Ag} / \mathrm{AgBr}$ (silver bromide). The corrected and normalized current potential plot is shown in Fig. 2(a) (orange curve) and compared with a $\mathrm{KCl}$ solution (red curve). Simultaneously, SERS spectra were acquired at representative potentials and the obtained currents are shown in Figs. S14 and S15 in the ESM. Control experiments without Raman acquisition and in the absence of nanoparticles in bromide solutions show no indication of oxidation (Figs. S16 and S17 in the ESM).

Based on the voltammogram an oxidation peak is observed at a potential of $0.0 \mathrm{~V}$, indicating the oxidation of silver to silver bromide (AgBr) $[80,91]$.

$$
\mathrm{Ag}+\mathrm{Br}^{-}(\mathrm{aq}) \rightleftharpoons \operatorname{AgBr}(\mathrm{s}) \downarrow+\mathrm{e}^{-}
$$

As expected, the oxidation potential is shifted to lower potentials due to the formation of thermodynamically more stable $\mathrm{AgBr}$ instead of $\mathrm{AgCl}$ (Fig. 2(a), red curve), in agreement with the Nernst equation and Refs. $[80,92,93]$. This is confirmed by ECSERS ( $c f r$ the central panel Fig. 2(b)). Even at $0 \mathrm{~V}$, a band at $170 \mathrm{~cm}^{-1}$ is observed, which is assigned to silver bromide ( $\mathrm{vAg}-\mathrm{Br}$ ) by partial oxidation to $\mathrm{AgBr}$ (at least at the surface) [90]. When increasing the voltage to $0.25 \mathrm{~V}$, the $\mathrm{vAg}-\mathrm{Br}$ band decreases (orange spectrum, Fig. 2(b)), indicating the formation of AgBr. Similar to chloride solutions, a complete loss of the citrate fingerprint is observed for higher potentials (Fig. S14 in the ESM).

In conclusion, when reversing the potential for both systems a clear electrochemical reduction peak (Figs. 1(a) and 2(a)) is acquired at 0.05 and $-0.15 \mathrm{~V}$, in the case of AgNPs in chloride (30 and $50 \mathrm{~nm}$ size of NPs) and in bromide (50 nm) solutions, respectively. This is spectroscopically confirmed by SERS results (Figs.1(b) and 2(b) and Figs. S7, S8, and S14 in the ESM).

Based on our results we conclude that the AgNPs undergo an almost complete and reversible oxidation to the oxidised $\mathrm{AgX}$ state and reduction to the elemental citrate-capped nanoparticles. Thus, we conclude that complementary experimental methods, such as EC-SERS, are required to characterize the molecular interaction at the nano-surface during an electrochemical experiment of the capping agent.

\subsection{Capping agent effect}

Having tracked and identified AgNP reactions by the signals of the capping agent in combination with the $\mathrm{Ag}-\mathrm{O}$ and $\mathrm{Ag}-\mathrm{X}$ signals in the previous section, next the effects of the capping agent were studied by exchanging citrate with PVP for $30 \mathrm{~nm}$ silver nanoparticles (AgPVP). EC-SERS was performed in a $50 \mathrm{mM} \mathrm{KCl}$ solution. Citrate and PVP-capped particles have the same size of $29 \pm 3 \mathrm{~nm}$ as shown by TEM measurement of the supplier (see the Experimental section and Figs. S1 and S3 in the ESM, respectively). However, the hydrodynamic radius of the PVP-capped particles is $51 \mathrm{~nm}$, which exceeds that of citratecapped particles $(34 \mathrm{~nm})$, as expected for a polymer serving as ligand.

The recorded current trace for the electrochemical transformation of AgNPs in $\mathrm{KCl}$ solution is shown in Fig. 3(a). The associated full potential and current plots as a function of time are provided in Fig. S18 in the ESM. We observed an oxidation peak at a potential of $0.16 \mathrm{~V}$ indicating the oxidation of $\mathrm{Ag}$ to $\mathrm{AgCl}$. Compared to citrate-capped particles the oxidation 

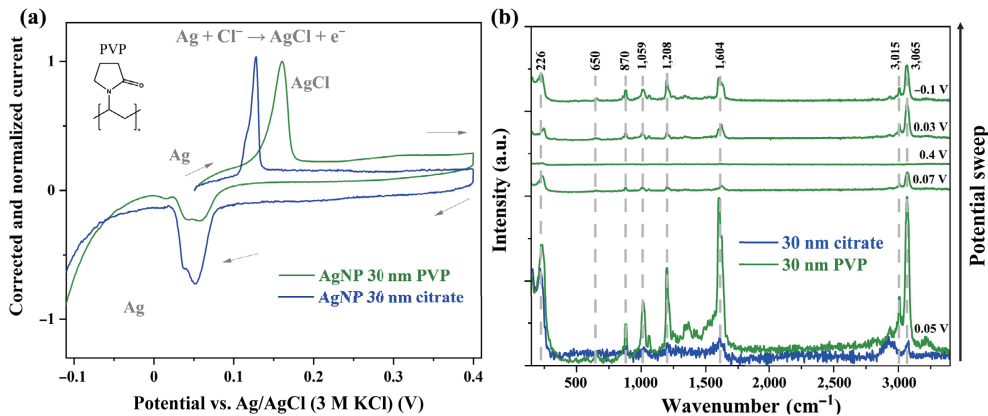

Figure 3 (a) Current potential diagram of $30 \mathrm{~nm}$ PVP-capped silver nanoparticles in $50 \mathrm{mM} \mathrm{KCl}$ (green) and $30 \mathrm{~nm}$ citrate-capped silver nanoparticles (blue) of the first scan. The potential was swept with $0.002 \mathrm{~V} \cdot \mathrm{s}^{-1}$. (b) SERS spectra in $50 \mathrm{mM} \mathrm{KCl}$ at representative potentials plotted against the intensity during the first cycle for PVP-capped $30 \mathrm{~nm}$ AgNPs (green) and compared to citrate-capped $30 \mathrm{~nm}$ AgNPs (blue). Raman modes assigned to PVP are highlighted in grey.

occurs at a slightly higher potential ( 0.16 vs. $0.12 \mathrm{~V})$, due to the thicker capping agent layer at the particle surface compared to citrate. The increase in capping agent layer results in a stronger potential drop within these layers as can be explained by an increased tunnelling distance for the electron. When decreasing again the potential, we find a reduction peak of $\mathrm{AgCl}$ at $0.04 \mathrm{~V}$. Control experiments are provided Figs. S10 and S19 in the ESM. Notably, the height of the reduction peak of PVP-capped silver particles (at $-0.1 \mathrm{~V}$ ) is smaller than the initial oxidation peak, indicating that the electrochemical sweeping is not fully reversible for PVP nanoparticles (at $0.05 \mathrm{~V}$ ). Thus, we conclude that the $\operatorname{Ag}(0)$ nanoparticles are not fully recovered during the reduction in the reverse cycle, resulting in a smaller signal intensity of the SERS. We attribute this to the detachment of $\mathrm{AgCl}$ particles from the surface or loss of their electrical connection to the electrode caused by the increased resistivity of $\mathrm{AgCl}$ vs. Ag nanoparticles or by a thicker capping agent layer. An additional representation of the non-normalized current is provided in Fig. S20 in the ESM.

The accompanying SERS spectra for PVP-capped AgNP at representative potentials are displayed in Fig. 3(b) (green curves), showing the Raman modes of PVP with bands at 650 ( $\delta 5$ ring), 870 ( $\delta 5$ ring), 1,059 (vCN), 1,208 (vCNC), 1,604 (vCN), and $3,017 \mathrm{~cm}^{-1}(\mathrm{v}=\mathrm{CH})$. The small fraction of the double bond is attributed to a residual fraction of monomeric $\mathrm{N}$-vinylpyrrolidone, an impurity likely co-adsorbed on the nanoparticle during its synthesis. The complete spectral dataset is provided in Fig. S21 in the ESM. Accompanying DFT calculations were performed for a $\mathrm{N}$-vinylpyrrolidone dimer and trimer, as a model for the PVP in the absence of the double bond. The results are summarized in Tables S5 and S6 in the ESM and compared to literature values in Table S7 in the ESM.

Similar to citrated-capped AgNPs, Raman modes associated with PVP molecules disappeared for potentials at $0.4 \mathrm{~V}$. As can be seen in Fig.3(b), upon oxidation the silver stretching mode is decreased, but still present, while no indication for a $\mathrm{Ag}-\mathrm{Cl}$ stretching mode is found. Nevertheless, a clear electrochemical oxidation signal of silver to $\mathrm{AgCl}$ is visible in the current response.

Based on these results we propose that only the surface-near fraction of the immobilized particles is oxidized, thus particles remain unreacted. This can be rationalized by the thicker capping agent layer formed by PVP instead of citrate, hindering electron tunnelling between electrode and nanoparticle and, thus, hampering NP oxidation. Sweeping back reductively, the PVP signal is restored upon electrochemical reduction back to silver.

Furthermore, we notice that for PVP-capped nanoparticles, Raman peaks are better resolved in the initial spectrum at $0.05 \mathrm{~V}$ compared to the final recorded at $-0.1 \mathrm{~V}$, whereas for citratecapped nanoparticles (of both sizes) the SERS bands are more pronounced after nanoparticle reconstruction. In general, in case of PVP the spectral bands are better defined than in case of citrate. Given that PVP has a larger hydrodynamic radius than citrate (51 and $34 \mathrm{~nm}$ for PVP and citrate-capped NPs, respectively), particles of a larger roughness may be formed upon capping with PVP compared to those prepared with citrate as a reducing and capping agent. This altered particle roughness might result in an improved SERS enhancement. In summary, we find that both PVP and citrate-capped AgNPs undergo a chemically reversible electrochemical oxidation to silver chloride. This is confirmed by EC-SERS operando spectroscopy upon application of an electrochemical potential. This study shows that electrolyte solutions and laser radiation have a direct influence on the structure of nanoparticles and their capping agents. Independent of the capping agent, silver nanoparticles tend to form a silver halide layer on the surface.

\section{Conclusions}

In this work, the chemical transformation and reactivity of silver nanoparticles upon oxidation and reduction under different experimental conditions are studied by coupled electrochemical SERS under operando conditions monitoring the Raman bands assigned to the capping agent during the reaction. While within our experimental sensitivity no systematic dependence of the particle size on the reactivity is observed, any change of the halide anion in the electrolyte as well as the type of the capping agent is found to substantially affect the reactivity of the particles. We find that the role of the capping agent in (electro-) chemical reactions of nanoparticles has been underestimated significantly in the past. Thus, we suggest considering the choice of capping agent as an important design criterion jointly with criteria like particle size, shape, and composition.

Additionally, we present that EC-SERS opens a door to study photochemical processes of capping agents at the surface of nanoparticles. The ability to detect reactions of the capping agents might be utilized in future studies to decipher adsorption processes on nanoparticles, like detection of biological molecules in a drug test [94-96] or catalytic reactions on the surface, allowing to quantify catalytic reactivity of nanomaterials.

\section{Acknowledgements}

K. W. acknowledges the German Chemical Industry Fund (FCI Kekule Stipendium). This work was supported by the Research Training group "Confinement-controlled Chemistry" funded by the Deutsche Forschungsgemeinschaft (DFG) (No. GRK2376/331085229). K. T. thanks the Ministry of Innovation, Science and Research of North Rhine-Westphalia for funds (NRW Rückkehrerprogramm). This work was funded by the Deutsche Forschungsgemeinschaft (DFG, German Research Foundation) under Germany's Excellence Strategy-EXC 2033-90677874RESOLV and the European Research Council (ERC) under the European Union's Horizon 2020 research and innovation programme (MITICAT; grant agreement No. 949724). The 
authors thank Dr. J. Deichmöller for initial help and fruitful discussion.

Funding note: Open Access funding enabled and organized by Projekt DEAL

Electronic Supplementary Material: Supplementary material (tables of Raman modes, TEM images, current and potential plots of experiments conducted with SERS of AgNPs, current and potential plots of experiments conducted without SERS of AgNPs, current and potential plots of experiments conducted in the absence of AgNPs) is available in the online version of this article at https://doi.org/10.1007/s12274-021-3999-2.

Open Access This article is licensed under a Creative Commons Attribution 4.0 International License, which permits use, sharing, adaptation, distribution and reproduction in any medium or format, as long as you give appropriate credit to the original author(s) and the source, provide a link to the Creative Commons licence, and indicate if changes were made.

The images or other third party material in this article are included in the article's Creative Commons licence, unless indicated otherwise in a credit line to the material. If material is not included in the article's Creative Commons licence and your intended use is not permitted by statutory regulation or exceeds the permitted use, you will need to obtain permission directly from the copyright holder.

To view a copy of this licence, visit http://creativecommons. org/licenses/by/4.0/.

\section{References}

[1] McClements, D. J.; Xiao, H. Is nano safe in foods? Establishing the factors impacting the gastrointestinal fate and toxicity of organic and inorganic food-grade nanoparticles. npj Sci. Food 2017, 1, 6.

[2] Chernousova, S.; Epple, M. Silver as antibacterial agent: Ion, nanoparticle, and metal. Angew. Chem., Int. Ed. 2013, 52, $1636-1653$.

[3] Wong, K. K. Y.; Cheung, S. O. F.; Huang, L. M.; Niu, J.; Tao, C.; Ho, C. M.; Che, C. M.; Tam, P. K. H. Further evidence of the antiinflammatory effects of silver nanoparticles. ChemMedChem 2009, 4, $1129-1135$.

[4] Hofmann-Amtenbrink, M.; Grainger, D. W.; Hofmann, H. Nanoparticles in medicine: Current challenges facing inorganic nanoparticle toxicity assessments and standardizations. Nanomedicine 2015, 11, 1689-1694.

[5] Matsuhisa, N.; Inoue, D.; Zalar, P.; Jin, H.; Matsuba, Y.; Itoh, A.; Yokota, T.; Hashizume, D.; Someya, T. Printable elastic conductors by in situ formation of silver nanoparticles from silver flakes. Nat. Mater. 2017, 16, 834-840.

[6] Shahidi, S. Magnetic nanoparticles application in the textile industry-A review. J. Ind. Text. 2019, 50, 970-989.

[7] Cota-Arriola, O.; Cortez-Rocha, M. O.; Burgos-Hernández, A.; Ezquerra-Brauer, J. M. Plascencia-Jatomea, M. Controlled release matrices and micro/nanoparticles of chitosan with antimicrobial potential: Development of new strategies for microbial control in agriculture. J. Sci. Food Agric. 2013, 93, 1525-1536.

[8] Prasad, R.; Kumar, V.; Kumar, M.; Wang, S. Q. Fungal nanobionics: Principles and applications Springer: Singapore, 2018.

[9] Peng, K. Q.; Wang, X.; Wu, X. L.; Lee, S. T. Platinum nanoparticle decorated silicon nanowires for efficient solar energy conversion. Nano Lett. 2009, 9, 3704-3709.

[10] Dai, L. M.; Chang, D. W.; Baek, J. B.; Lu, W. Carbon nanomaterials for advanced energy conversion and storage. Small 2012, 8, $1130-1166$.

[11] Zeng, S. W.; Yong, K. T.; Roy, I.; Dinh, X. Q.; Yu, X.; Luan, F. A review on functionalized gold nanoparticles for biosensing applications. Plasmonics 2011, 6, 491-506.
[12] Linnemann, J.; Kanokkanchana, K.; Tschulik, K. Design strategies for electrocatalysts from an electrochemist's perspective. ACS Catal. 2021, 11, 5318-5346.

[13] Hervés, P.; Pérez-Lorenzo, M.; Liz-Marzán, L. M.; Dzubiella, J.; Lu, Y.; Ballauff, M. Catalysis by metallic nanoparticles in aqueous solution: Model reactions. Chem. Soc. Rev. 2012, 41, 5577-5587.

[14] Raimondi, F.; Scherer, G. G.; Kötz, R.; Wokaun, A. Nanoparticles in energy technology: Examples from electrochemistry and catalysis. Angew. Chem., Int. Ed. 2005, 44, 2190-2209.

[15] Zhu, C. Z.; Dong, S. J. Recent progress in graphene-based nanomaterials as advanced electrocatalysts towards oxygen reduction reaction. Nanoscale 2013, 5, 1753-1767.

[16] El Arrassi, A.; Liu, Z. B.; Evers, M. V.; Blanc, N.; Bendt, G.; Saddeler, S.; Tetzlaff, D.; Pohl, D.; Damm, C.; Schulz, S. et al. Intrinsic activity of oxygen evolution catalysts probed at single $\mathrm{CoFe}_{2} \mathrm{O}_{4}$ nanoparticles. J. Am. Chem. Soc. 2019, 141, 9197-9201.

[17] Zhou, Z. Y.; Tian, N.; Li, J. T.; Broadwell, I.; Sun, S. G. Nanomaterials of high surface energy with exceptional properties in catalysis and energy storage. Chem. Soc. Rev. 2011, 40, 4167-4185.

[18] Bell, A. T. The impact of nanoscience on heterogeneous catalysis. Science 2003, 299, 1688-1691.

[19] Alkire, R. C.; Kolb, D. M.; Lipkowski, J. Electrocatalysis: Theoretical Foundations and Model Experiments; Wiley-VCH: Weinheim, 2013.

[20] Yang, T.-H.; Ahn, J.; Shi, S.; Qin, D. Understanding the role of poly(vinylpyrrolidone) in stabilizing and capping colloidal silver nanocrystals. ACS Nano, in press, https://doi.org/10.1021/ acsnano.1c01668.

[21] Wonner, K.; Evers, M. V.; Tschulik, K. The electrochemical dissolution of single silver nanoparticles enlightened by hyperspectral dark-field microscopy. Electrochim. Acta 2019, 301, $458-464$.

[22] Wonner, K.; Evers, M. V.; Tschulik, K. Simultaneous opto- and spectro-electrochemistry: Reactions of individual nanoparticles uncovered by dark-field microscopy. J. Am. Chem. Soc. 2018, 140, $12658-12661$.

[23] Wonner, K.; Rurainsky, C.; Tschulik, K. Operando studies of the electrochemical dissolution of silver nanoparticles in nitrate solutions observed with hyperspectral dark-field microscopy. Front. Chem. 2020, 7, 912.

[24] Batchelor-McAuley, C.; Martinez-Marrades, A.; Tschulik, K.; Patel, A. N.; Combellas, C.; Kanoufi, F.; Tessier, G.; Compton, R. G. Simultaneous electrochemical and 3D optical imaging of silver nanoparticle oxidation. Chem. Phys. Lett. 2014, 597, 20-25.

[25] Lemineur, J. F.; Noël, J. M.; Courty, A.; Ausserré, D.; Combellas, C.; Kanoufi, F. In situ optical monitoring of the electrochemical conversion of dielectric nanoparticles: From multistep charge injection to nanoparticle motion. J. Am. Chem. Soc. 2020, 142, 7937-7946.

[26] Brasiliense, V.; Clausmeyer, J.; Berto, P.; Tessier, G.; Combellas, C.; Schuhmann, W.; Kanoufi, F. Monitoring cobalt-oxide single particle electrochemistry with subdiffraction accuracy. Anal. Chem. 2018, 90, 7341-7348.

[27] Doneux, T.; Bouffier, L.; Goudeau, B.; Arbault, S. Coupling electrochemistry with fluorescence confocal microscopy to investigate electrochemical reactivity: A case study with the resazurin-resorufin fluorogenic couple. Anal. Chem. 2016, 88, $6292-6300$.

[28] Hao, R.; Fan, Y. S.; Zhang, B. Imaging dynamic collision and oxidation of single silver nanoparticles at the electrode/solution interface. J. Am. Chem. Soc. 2017, 139, 12274-12282.

[29] Wilson, A. J.; Marchuk, K.; Willets, K. A. Imaging electrogenerated chemiluminescence at single gold nanowire electrodes. Nano Lett. $\mathbf{2 0 1 5}, 15,6110-6115$.

[30] Bard, A. J. Electrogenerated Chemiluminescence; Marcel Dekker: New York, 2004.

[31] Forster, R. J.; Bertoncello, P.; Keyes, T. E. Electrogenerated chemiluminescence. Annu. Rev. Anal. Chem. 2009, 2, 359-385.

[32] Zybin, A.; Kuritsyn, Y. A.; Gurevich, E. L.; Temchura, V. V.; Überla, K.; Niemax, K. Real-time detection of single immobilized nanoparticles by surface Plasmon resonance imaging. Plasmonics 2010, 5, 31-35.

[33] Fang, Y. M.; Wang, W.; Wo, X.; Luo, Y. S.; Yin, S. W.; Wang, Y. X.; Shan, X. N.; Tao, N. J. Plasmonic imaging of electrochemical 
oxidation of single nanoparticles. J. Am. Chem. Soc. 2014, 136, 12584-12587.

[34] Wang, Y. X.; Shan, X. N.; Wang, H.; Wang, S. P.; Tao, N. J. Plasmonic imaging of surface electrochemical reactions of single gold nanowires. J. Am. Chem. Soc. 2017, 139, 1376-1379.

[35] Solla-Gullón, J.; Gómez, R.; Aldaz, A.; Pérez, J. M. A combination of SERS and electrochemistry in Pt nanoparticle electrocatalysis: Promotion of formic acid oxidation by ethylidyne. Electrochem. Commun. 2008, 10, 319-322.

[36] Plieth, W.; Dietz, H.; Anders, A.; Sandmann, G.; Meixner, A.; Weber, M.; Kneppe, H. Electrochemical preparation of silver and gold nanoparticles: Characterization by confocal and surface enhanced Raman microscopy. Surf. Sci. 2005, 597, 119-126.

[37] Tian, Z. Q.; Ren, B. Adsorption and reaction at electrochemical interfaces as probed by surface-enhanced Raman spectroscopy. Annu. Rev. Phys. Chem. 2004, 55, 197-229.

[38] Di Martino, G.; Turek, V. A.; Lombardi, A.; Szabó, I.; De Nijs, B.; Kuhn, A.; Rosta, E.; Baumberg, J. J. Tracking nanoelectrochemistry using individual plasmonic nanocavities. Nano Lett. 2017, 17, 4840-4845.

[39] Willets, K. A. Probing nanoscale interfaces with electrochemical surface-enhanced Raman scattering. Curr. Opin. Electrochem. 2019, $13,18-24$.

[40] Yeo, B. S.; Bell, A. T. Enhanced activity of gold-supported cobalt oxide for the electrochemical evolution of oxygen. J. Am. Chem. Soc. 2011, 133, 5587-5593.

[41] Hwang, H.; Kim, S. H.; Yang, S. M. Microfluidic fabrication of SERS-active microspheres for molecular detection. Lab Chip 2011, 11, 87-92.

[42] Tan, R. Z.; Agarwal, A.; Balasubramanian, N.; Kwong, D. L.; Jiang, Y.; Widjaja, E.; Garland, M. 3D arrays of SERS substrate for ultrasensitive molecular detection. Sens. Actuator A Phys. 2007, 139, $36-41$.

[43] He, R. X.; Liang, R.; Peng, P.; Zhou, Y. N. Effect of the size of silver nanoparticles on SERS signal enhancement. J. Nanopart. Res. 2017, 19, 267.

[44] Abdelsalam, M.; Bartlett, P. N.; Russell, A. E.; Baumberg, J. J.; Calvo, E. J.; Tognalli, N. G.; Fainstein, A. Quantitative electrochemical SERS of Flavin at a structured silver surface. Langmuir 2008, 24, 7018-7023.

[45] Abdelsalam, M. E.; Bartlett, P. N.; Baumberg, J. J.; Cintra, S.; Kelf, T. A.; Russell, A. E. Electrochemical SERS at a structured gold surface. Electrochem. Commun. 2005, 7, 740-744.

[46] Dick, L. A.; McFarland, A. D.; Haynes, C. L.; Van Duyne, R. P. Metal film over nanosphere (MFON) electrodes for surfaceenhanced Raman spectroscopy (SERS): Improvements in surface nanostructure stability and suppression of irreversible loss. J. Phys. Chem. B 2002, 106, 853-860.

[47] Ding, S. Y.; You, E. M.; Tian, Z. Q.; Moskovits, M. Electromagnetic theories of surface-enhanced Raman spectroscopy. Chem. Soc. Rev. 2017, 46, 4042-4076.

[48] Schlücker, S. Surface-enhanced Raman spectroscopy: Concepts and chemical applications. Angew. Chem., Int. Ed. 2014, 53, 4756-4795.

[49] Amendola, V.; Pilot, R.; Frasconi, M.; Maragò, O. M.; Iatì, M. A. Surface Plasmon resonance in gold nanoparticles: A review. J. Phys. Condens. Matter 2017, 29, 203002.

[50] Cao, J.; Sun, T.; Grattan, K. T. V. Gold nanorod-based localized surface Plasmon resonance biosensors: A review. Sens. Actuators $B$ Chem. 2014, 195, 332-351.

[51] Mayer, K. M.; Hafner, J. H. Localized surface plasmon resonance sensors. Chem. Rev. 2011, 111, 3828-3857.

[52] Wilson, A. J.; Willets, K. A. Molecular plasmonics. Annu. Rev. Anal. Chem. 2016, 9, 27-43.

[53] Jing, C.; Rawson, F. J.; Zhou, H.; Shi, X.; Li, W. H.; Li, D. W.; Long, Y. T. New insights into electrocatalysis based on plasmon resonance for the real-time monitoring of catalytic events on single gold nanorods. Anal. Chem. 2014, 86, 5513-5518.

[54] Ma, Y. X.; Highsmith, A. L.; Hill, C. M.; Pan, S. L. Dark-field scattering spectroelectrochemistry analysis of hydrazine oxidation at au nanoparticle-modified transparent electrodes. J. Phys. Chem. C 2018, 122, 18603-18614.

[55] Cheng, W.; Compton, R. G. Electrochemical detection of nanoparticles by "nano-impact" methods. TrAC Trends Anal. Chem. 2014, 58, 79-89.
[56] Sundaresan, V.; Monaghan, J. W.; Willets, K. A. Visualizing the effect of partial oxide formation on single silver nanoparticle electrodissolution. J. Phys. Chem. C 2018, 122, 3138-3145.

[57] Little, C. A.; Batchelor-McAuley, C.; Ngamchuea, K.; Lin, C. H.; Young, N. P.; Compton, R. G. Coupled optical and electrochemical probing of silver nanoparticle destruction in a reaction layer. ChemistryOpen 2018, 7, 370-380.

[58] El-Nour, K. M. M. A.; Eftaiha, A.; Al-Warthan, A.; Ammar, R. A. A. Synthesis and applications of silver nanoparticles. Arab. J. Chem. 2010, 3, 135-140.

[59] Tschulik, K.; Batchelor-McAuley, C.; Toh, H. S.; Stuart, E. J. E.; Compton, R. G. Electrochemical studies of silver nanoparticles: A guide for experimentalists and a perspective. Phys. Chem. Chem. Phys. 2014, 16, 616-623.

[60] Zhang, F.; Edwards, M. A.; Hao, R.; White, H. S.; Zhang, B. Collision and oxidation of silver nanoparticles on a gold nanoband electrode. J. Phys. Chem. C 2017, 121, 23564-23573.

[61] Ustarroz, J.; Kang, M.; Bullions, E.; Unwin, P. R. Impact and oxidation of single silver nanoparticles at electrode surfaces: One shot versus multiple events. Chem. Sci. 2017, 8, 1841-1853.

[62] Oja, S. M.; Robinson, D. A.; Vitti, N. J.; Edwards, M. A.; Liu, Y. W.; White, H. S.; Zhang, B. Observation of multipeak collision behavior during the electro-oxidation of single $\mathrm{Ag}$ nanoparticles. $J$. Am. Chem. Soc. 2017, 139, 708-718.

[63] Robinson, D. A.; Liu, Y. W.; Edwards, M. A.; Vitti, N. J.; Oja, S M.; Zhang, B.; White, H. S. Collision dynamics during the electrooxidation of individual silver nanoparticles. J. Am. Chem. Soc. 2017, 139, 16923-16931.

[64] Salemmilani, R.; Mirsafavi, R. Y.; Fountain, A. W.; Moskovits, M.; Meinhart, C. D. Quantitative surface-enhanced Raman spectroscopy chemical analysis using citrate as an in situ calibrant. Analyst 2019, 144, 1818-1824.

[65] Awada, C.; Traboulsi, H. Effect of $\mathrm{pH}$ and nanoparticle capping agents on $\mathrm{Cr}$ (III) monitoring in water: A kinetic way to control the parameters of ultrasensitive environmental detectors. Micromachines 2020, 11, 1045.

[66] Smith, J. G.; Jain, P. K. The ligand shell as an energy barrier in surface reactions on transition metal nanoparticles. J. Am. Chem. Soc. 2016, 138, 6765-6773.

[67] Gorbachevskii, M. V.; Kopitsyn, D. S.; Kotelev, M. S.; Ivanov, E. V.; Vinokurov, V. A.; Novikov, A. A. Amplification of surfaceenhanced Raman scattering by the oxidation of capping agents on gold nanoparticles. RSC Adv. 2018, 8, 19051-19057.

[68] Brasiliense, V.; Patel, A. N.; Martinez-Marrades, A.; Shi, J.; Chen, Y.; Combellas, C.; Tessier, G.; Kanoufi, F. Correlated electrochemical and optical detection reveals the chemical reactivity of individual silver nanoparticles. J. Am. Chem. Soc. 2016, 138, 3478-3483.

[69] Zaleski, S.; Cardinal, M. F.; Klingsporn, J. M.; Van Duyne, R. P. Observing single, heterogeneous, one-electron transfer reactions. $J$. Phys. Chem. C 2015, 119, 28226-28234.

[70] Kong, N.; Guo, J.; Chang, S.; Pan, J.; Wang, J. M.; Zhou, J. H.; Liu, J.; Zhou, H.; Pfeffer, F. M.; Liu, J. et al. Direct observation of amide bond formation in a plasmonic nanocavity triggered by single nanoparticle collisions. J. Am. Chem. Soc. 2021, 143, 9781-9790.

[71] Akhil, K.; Jayakumar, J.; Gayathri, G.; Khan, S. S. Effect of various capping agents on photocatalytic, antibacterial and antibiofilm activities of $\mathrm{ZnO}$ nanoparticles. J. Photochem. Photobiol. B Biol. 2016, 160, 32-42.

[72] Campisi, S.; Schiavoni, M.; Chan-Thaw, C.; Villa, A. Untangling the role of the capping agent in nanocatalysis: Recent advances and perspectives. Catalysts 2016, 6, 185.

[73] Suherman, A. L.; Zampardi, G.; Amin, H. M. A.; Young, N. P.; Compton, R. G. Tannic acid capped gold nanoparticles: Capping agent chemistry controls the redox activity. Phys. Chem. Chem. Phys. 2019, 21, 4444-4451.

[74] Niu, Z. C; Li, Y. D. Removal and utilization of capping agents in nanocatalysis. Chem. Mater. 2014, 26, 72-83.

[75] Byers, C. P.; Hoener, B. S.; Chang, W. S.; Link, S.; Landes, C. F. Single-particle Plasmon voltammetry (spPV) for detecting anion adsorption. Nano Lett. 2016, 16, 2314-2321.

[76] Tanner, E. E. L.; Sokolov, S. V.; Young, N. P.; Batchelor-McAuley, 
C.; Compton, R. G. Fluorescence electrochemical microscopy: Capping agent effects with ethidium bromide/DNA capped silver nanoparticles. Angew. Chem. 2017, 129, 12925-12928.

[77] Tanner, E. E. L.; Tschulik, K.; Tahany, R.; Jurkschat, K.; BatchelorMcAuley, C.; Compton, R. G. Nanoparticle capping agent dynamics and electron transfer: Polymer-gated oxidation of silver nanoparticles. J. Phys. Chem. C 2015, 119, 18808-18815.

[78] Toh, H. S.; Jurkschat, K.; Compton, R. G. The influence of the capping agent on the oxidation of silver nanoparticles: Nano-impacts versus stripping voltammetry. Chem.-Eur. J. 2015, 21, 2998-3004.

[79] Han, Y.; Lupitskyy, R.; Chou, T. M.; Stafford, C. M.; Du, H.; Sukhishvili, S. Effect of oxidation on surface-enhanced Raman scattering activity of silver nanoparticles: A quantitative correlation. Anal. Chem. 2011, 83, 5873-5880.

[80] Saw, E. N.; Blanc, N.; Kanokkanchana, K.; Tschulik, K. Timeresolved impact electrochemistry-A new method to determine diffusion coefficients of ions in solution. Electrochim. Acta 2018, 282, 317-323.

[81] Takeuchi, Y.; Fujita, T.; Takeyasu, N. Plasmon-mediated chemical transformation from alkane to alkene on a silver nanoparticle array under $532 \mathrm{~nm}$ excitation. Phys. Chem. Chem. Phys. 2019, 21, $7502-7507$.

[82] Levard, C.; Mitra, S.; Yang, T.; Jew, A. D.; Badireddy, A. R.; Lowry, G. V.; Brown, G. E. Effect of chloride on the dissolution rate of silver nanoparticles and toxicity to E. coli. Environ. Sci. Technol. 2013, 47, 5738-5745.

[83] Toh, H. S.; Batchelor-McAuley, C.; Tschulik, K.; Compton, R. G. Electrochemical detection of chloride levels in sweat using silver nanoparticles: A basis for the preliminary screening for cystic fibrosis. Analyst 2013, 138, 4292-4297.

[84] Naja, G.; Bouvrette, P.; Hrapovic, S.; Luong, J. H. T. Raman-based detection of bacteria using silver nanoparticles conjugated with antibodies. Analyst 2007, 132, 679-686.

[85] Revie, R. W. Uhlig's Corrosion Handbook, 3rd ed.; Wiley: Hoboken, 2011.

[86] Kolwas, K. Decay dynamics of localized surface plasmons: Damping of coherences and populations of the oscillatory Plasmon modes. Plasmonics 2019, 14, 1629-1637.

[87] Moon, S. W.; Tsalu, P. V.; Ha, J. W. Single particle study: Size and chemical effects on Plasmon damping at the interface between adsorbate and anisotropic gold nanorods. Phys. Chem. Chem. Phys. 2018, 20, 22197-22202.

[88] Tsalu, P. V.; Kim, G. W.; Hong, J. W.; Ha, J. W. Homogeneous localized surface Plasmon resonance inflection points for enhanced sensitivity and tracking Plasmon damping in single gold bipyramids. Nanoscale 2018, 10, 12554-12563.

[89] Dondapati, S. K.; Ludemann, M.; Müller, R.; Schwieger, S.; Schwemer, A.; Händel, B.; Kwiatkowski, D.; Djiango, M.; Runge, E.; Klar, T. A. Voltage-induced adsorbate damping of single gold nanorod plasmons in aqueous solution. Nano Lett. 2012, 12, $1247-1252$.

[90] Park, H.; Lee, S. B.; Kim, M. S.; Kim, K. Effects on silver-surfaceenhanced Raman spectroscopy by competitive adsorption of hydroxide and halide ions. Chem. Phys. 1992, 161, 265-272.

[91] Bartlett, T. R.; Sokolov, S. V.; Compton, R. G. Electrochemical nanoparticle sizing via nano-impacts: How large a nanoparticle can be measured? ChemistryOpen 2015, 4, 600-605.

[92] Bard, A. J.; Faulkner, L. R. Electrochemical Methods: Fundamentals and Applications, 2nd ed.; Wiley: New York, 2001.

[93] Nernst, W. Die elektromotorische wirksamkeit der Jonen. Z. Phys. Chem. 1889, $4 U, 129-181$.

[94] Chen, C. P.; Liu, W. F.; Tian, S. P.; Hong, T. T. Novel surfaceenhanced Raman spectroscopy techniques for DNA, protein and drug detection. Sensors 2019, 19, 1712.

[95] Baia, M.; Toderas, F.; Baia, L.; Popp, J.; Astilean, S. Probing the enhancement mechanisms of SERS with p-aminothiophenol molecules adsorbed on self-assembled gold colloidal nanoparticles. Chem. Phys. Lett. 2006, 422, 127-132.

[96] Jahangirian, H.; Kalantari, K.; Izadiyan, Z.; Rafiee-Moghaddam, R.; Shameli, K.; Webster, T. J. A review of small molecules and drug delivery applications using gold and iron nanoparticles. Int. J. Nanomedicine 2019, 14, 1633-1657. 